\title{
Farklı Nitelikte Çelloların Değerlendirilmesinde Rubrik Kullanımı
}

\section{The Usage of Rubric in Evaluation of Different Properties of Cellos}

\author{
Ozan Evrim TUNCA ${ }^{1}$ (1), Özgün DEMİ² [0
}

'Prof. Dr., Anadolu Üniversitesi Devlet Konservatuvarı Yaylı Çalgılar Anasanat Dalı, Eskişehir, Türkiye

${ }^{2}$ Arş. Gör., Anadolu Üniversitesi Devlet Konservatuvarı Yaylı Çalgılar Yapımı Anasanat Dalı, Eskişehir, Türkiye

ORCID: Ö.D. 0000-0002-4914-4844;

O.E.T. 0000-0002-3519-8761

\section{Sorumlu yazar/Corresponding author: Özgün Demir, \\ Anadolu Üniversitesi Devlet Konservatuvarı, Yayılı Çalgılar Yapımı Anasanat Dalı, Eskişehir, Türkiye \\ E-posta/E-mail: ozgund@anadolu.edu.tr}

Başvuru/Submitted: 28.11.2018

Revizyon Talebi/Revision Requested: 22.05.2019

Son Revizyon/Last Revision Received:

28.05.2019

Kabul/Accepted: 10.06 .2019

Online Yayın/Published Online: 11.06.2019

Atıf/Citation: Tunca, O. E. ve Demir, O. (2019). Farklı nitelikte çelloların değerlendirilmesinde rubrik kullanımı. Konservatoryum -

Conservatorium, 6(1), 1-20.

https://doi.org/10.26650/CONS2018-0013

\section{ÖZ}

Bu çalışmanın amacı yaylı çalgıların farklı ses gürlüğünde çalabilme yetenekleri, ses rengi çeşitliliği (ton zenginliği), seste vibrato üretimi, ses şiddetinin farklı teller veya registerlerdeki (tuşenin farklı bölümleri) eşitliği ve özgün ses tonu gibi özelliklerini objektif şekilde belirlemek amacıyla bir yöntem oluşturmaktır. Çalışma, betimsel bir araştırma olarak planlanmıştır. Çalışma grubu, Türkiye'nin İç Anadolu Bölgesi'ndeki bir üniversitesinin devlet konservatuvarı müzik bölümü çello sanat dalında görevli alanında uzman altı öğretim görevlisi, bir gönüllü lisans çello bölümü öğrencisi ve üç farklı çellodan oluşmaktadır. Nicel veriler Yaylı Çalgı Değerlendirme Rubriği (YÇR) aracılığıyla elde edilmiştir. Elde edilen bulgular tablolaştırılarak değerlendirmeler yapılmıştır. Edinilen bulgulara göre çalgı ses niteliği değerlendirmesinde nesnel yaklaşımın önemi ortaya çıkmıştır. Rubrik, üç farklı çalgının ses karakterleri arasındaki birbirine benzer noktalar ile birbirlerine göre güçlü ve zayıf yönleri başarıyla ortaya çıkarmıştır. Bir dereceli puanlama anahtarı olan rubriğin öznel değerlendirmeleri, ölçülebilir nesnel sonuçlara başarıyla dönüştürebildiği sonucuna ulaşılmış ve rubriğin bu amaçla kullanımına ilişskin çözüm önerilerinde bulunulmuştur.

Anahtar Kelimeler: Çello, Rubrik, Tını

\section{ABSTRACT}

The purpose of this research is to develop a method to test different properties of a given violoncello. The properties tested are the variety of color, vibrato production, capacity of volume, equality of sound among different registers, characteristic tone. The study is designed as descriptive research. The study group of the study consists of; three different handmade cellos, six expert lecturers on the field and a volunteer undergraduate student from cello arts of the music department of the conservatory of a state university in Central Anatolia, Turkey. Data have been obtained by a string instrument rubric (YÇR). The findings were tabulated and evaluations were made. According to the findings obtained, the importance of the objective approach in evaluating the sound properties of the instruments has emerged. The rubric was able to reveal the instruments with similar sound characteristics and distinguish the strengths of them. The graded scoring key rubric was found to be successful for turning the subjective evaluations into measurable objective results and solution proposals have been made for the usage of rubric for this specific purpose.

Keywords: Cello, Rubric, Tone 


\section{EXTENDED ABSTRACT}

There are a lot of new studies that can be done on this subject since there are few academic studies about the instrument than other art branches both in our country and in the World. Sound production and tonal differences between different quality instruments are also one of these research topics. The purpose of this research is to develop a tool to test different properties of a given violoncello. The properties tested are the variety of color, vibrato production, capacity of volume, equality of sound among different registers, characteristic tone. The study is designed as descriptive research. Several professors of cello and a volunteer undergraduate student have participated in the study. Handmade cellos were used for the research. The model of this research is a single scan model from general screening models. Qualitative findings have been gathered by scanning sources. In collecting these data, native and foreign books, theses, articles, reports and etc. related to the subject have been utilized. In addition, experts with over ten years of lecturing experience in conservatory have been consulted about the criteria of instrument evaluation. Quantitative data have been obtained by a string instrument rubric (YÇR). In this study which is descriptive research, instead of the universe-sample model, a study group was established in accordance with the type of research. The study group of the study consists of; three different handmade cellos, six expert lecturers on the field and a volunteer undergraduate student from Cello Arts of Music Department of Conservatory of a state university in Central Anatolia. For the research purposes, expert opinions have been taken and literature has been examined thus the evaluation criteria have been determined as the loudness of the instruments, diversity of the sound color, the equality of the sound on different strings or registers, and the vibrato production. To evaluate these criteria, appropriate pieces have been selected with field experts. Afterward, the student who would take part in research has studied the pieces individually. After this process, the student has been asked to execute his performance with three different handmade cellos. Video recording has been done in order to observe and examine the performance of the student with different instruments. The records of the students' performance with different instruments have been evaluated comparatively by six experts from the State Conservatory Cello Arts. Experts have not been told which instrument was which, and have been asked to evaluate as "instrument 1-2-3". In the evaluation process, the String Instrument Evaluation Form (Rubric), which had been developed by the researchers and evaluated by expert opinions, has been used to evaluate the sound characteristics of the in- 
strument in seven criteria. Findings based on differences between performances from different instruments have been discussed by the experts. Quantitative data obtained by the String Instrument Evaluation Form have been analyzed by SPSS (Statistical Package for the Social Sciences) data processing software. Rubric, the graded scoring key, has been successfully applied in this study as an evaluation method that allows objectivity at a measurable level. By providing a scoring chart according to the success levels in the evaluated criteria, it has enabled accurate scoring. According to the obtained data, the total scores of the three cellos compared in this study has been close to each other and they have had similar results according to the experts. However, they have been separated from each other by their performances between criteria. These differences have been able to be distinguished clearly by the detailed scoring system of the Rubric. The rubric has been able to reveal the instruments with similar sound characteristics and distinguish the strengths of them. It has revealed the difference in sound characteristics between old and new instruments. The research also has shown that the rubric is a useful method to reveal the weaknesses of the instruments in order to improve them in the future. 


\section{Giriş}

Türkiye'de çello eğitimi güzel sanatlar liseleri, bazı güzel sanatlar fakülteleri, eğitim fakülteleri ve devlet konservatuvarları müzik bölümleri ve pek çok özel müzik okulunda gerçekleşmektedir. Ayrıca çellistler devlete bağlı veya özel orkestraların kadrolarında kendilerine yer bulur ya da üniversitelerde akademik kadrolara atanırlar. Genel olarak ülkemizde çellistlerin sayısı artmakta ve nitelikleri ilerlemektedir. Bir çellistin yaşamında ses verdiği çelloların kalitesi çok önemlidir. Çalgıdan iyi sesler çıkarabilmek konusunda kendisini geliştirmekte olan kişilerin en büyük ihtiyacı doğal olarak bu ihtiyaçlarına yanıt verebilecek çalgılarının olmasıdır. Öğrenci ya da profesyonel, bir çellist çalgı seçme becerisinde ne kadar gelişme kaydederse uzun vadede kendine uygun bir çalgıya sahip olma olasılığı da o oranda artar. Doğru çalg1 seçimi, bir çellistin aldığ etkisini ve profesyonel kariyerinin gelişimini olumlu yönde etkileyecektir.

Tüm profesyonel yaylı çalgı icracıları için en temel konulardan birisi doğru ve etkili ses üretebilmektir. Kesin entonasyon, zengin ve karakteristik ses rengi, teller arasında ses üretiminin eşitliği, iyi vibrato üretimi icracıyla olduğu kadar kullanılan çalgıyla da doğrudan ilgilidir. İcracılar çalgıları nitelik olarak birbirinden ayırırken pek seçenekleri olmadığından sadece öznel değerlendirmede bulunmaktadırlar. Bu da kişiler arası değerlendirmelerde, genel tutarlılığı düşürmekte ve çalgının niteliklerinin tanımlanmasında net olmayan yargilara varılmasına neden olabilmektedir. Bu nedenle, farklı özelliklere sahip müzik enstrümanlarını değerlendirirken, değerlendiricinin insan olduğu bir çalışmada tutarlı karşılaştırmalar yapabilmek için içerisindeki kategorilerin ve tanımların açıkça belirlenmiş olduğu bir araca ihtiyaç duyulmaktadır. Bu bağlamda araştırmanın problem cümlesi "Farklı niteliklere sahip çelloların değerlendirilmesinde rubrik kullanımının tutarlı sonuçlar elde etmede faydası olabilir mi?" biçiminde oluşturulmuştur.

Bu çalışmanın amacı yaylı çalgıların farklı gürlükte çalabilme yetenekleri, ses rengi çeşitliliği , vibrato üretimi, sesin farklı teller veya registerlerdeki ses eşitliği, özgün ses tonu gibi özelliklerini objektif şekilde belirlemek amaciyla bir araç oluşturmak ve bu aracın kullanılabilirliğini değerlendirmektir.

Rubriğin çalgı değerlendirmesi amacıyla kullanımı konusunda literatürde yapılmış herhangi bir çalışma mevcut değildir. Bu anlamda çalışma, alanda yapılmış bir öncü çalışma olma özelliği taşımaktadır. Araştırma ayrıca, gelecekte yapılacak olan benzer çalışmala- 
ra öncü olması yanında, enstrüman yapımcılarına çalgılarının zayıf yönlerini belirlemek amacıyla uygun değerlendirme aracı geliştirmekte yardımcı olacaktır.

Çalgıların ömürlerinin uzun olması, tınılarının zengin, gürlüklerinin yüksek olması gibi pek çok kriteri değerlendirmek için çeşitli yöntemler geliştirmek önemli bir ihtiyaçtır. Ayrıca pek çok çalgının art arda seçilmesi (söz gelimi kurumsal alımlar) ya da kalite kontrolü gerekli olduğunda sağlıklı ve hızlı değerlendirme yapabilmek için de bir ölçeğe ihtiyaç vardır.

Çello, diğer adı ile viyolonsel kemandan sonra en popüler yaylı çalgılardan biridir. Çellonun eğitimi, solistleri ve repertuvarının yanında yapısı, yapılış süreci ve farklı kaliteleri hakkında da araştırmalara ihtiyaç olduğu açıktır. Ülkemizde bu konuda yapılmış akademik çalışmalar diğer pek çok alana göre daha az sayıda olduğundan, araştırmacıların çalgı yapısı, yapılış süreci, alım satımı, kullanımı ve farklı düzeydeki kalitelerin tespiti konularında pek çok çalışma yürütmeleri mümkündür. Farklı düzeydeki çalgılar arasındaki ses üretimi ve tonal farklılıklar da bu araştırma konularından birisidir.

Bütün müzik çalgılarından beklenen en temel özellikler; çalgının iyi ses vermesi, rahat çalınabilir olması ve dengeli bir tonal karaktere sahip olmasıdır. Bir çalgının iyi ton vermesi için üst ve alt tahtanın birbirine uyumlu ve iyi bir işçilikle yapılması, usta bir çalgı yapımcısının becerisi ve hassasiyeti gereklidir. Orantısı bozuk, iyi bir işçiliğe sahip olmayan, kusurlu bir yaylı çalgıda en iyi malzemeler dahi kullanılmış olsa aranılan tonal güzelliğe ulaşılamaz (Yaygıngöl, 2006, s. 140, 151).

Yaylı çalgıların ton kalitelerinde, kullanılan ağaç ve iş̧̧iliğin kalitesi büyük pay sahibidir. Mükemmel işçilikle yapılıp, uygun teller ve iyi kalite bir arşe ile çalınan keman, aynı teller ve arşe ile kombine edilecek daha zayıf işçilikli bir kemana göre daha iyi ses üretebilecektir. Bununla beraber yaylı çalgı yapımı kompleks bir projedir, yüksek kalite yaylı çalgıları geniş ölçekte seri üretim olarak üretmek mümkün değildir. Bir lutiyeye çalgı siparişi verildiğinde, yapımcı, icracının ihtiyaçlarına göre malzeme seçip, ihtiyaçlarını karşılayacak yapıda özel bir çalgı üretecektir. Fabrikasyon çalgı üretiminde ise bu mümkün değildir ve daha genel bir üretim yapılır (Pagliaro, 2015, s. 75-77, 90).

Teorik olarak daha yüksek kaliteyle üretilmiş bir viyolonsel ses aralığı boyunca daha zengin bir tınısal ses karakterine sahip olacak ve bu sayede ses aralığı içindeki her notay1 daha güçlü vererek dinleyicilere daha memnun edici gelecektir (Duff, 1985, s. 17). 
Ayrıca Ang1 ve Birer (2013)'in yaptıkları çalışma göstermiştir ki çalgı kalitesiyle entonasyon arasında bir ilişki bulunmaktadır ve bu icracılarca hissedilebilmektedir. Kötü bir çalgı çalan öğrenci, icra için yeterli tüm çabayı göstermesine rağmen yine de yeterince başarılı olamayacak ve yaptığı işten zevk alamayacaktır. Çalgı kalitesinin, müziğe başlangıç aşamasında yapılan işten zevk alınabilmesinde yeri çok önemlidir, kötü bir çalgıyla başlayıp sonradan iyi bir çalgıya geçilmesi gibi yanlış bir görüşten uzak durmak gereklidir (s. 66-68).

İmik ve Haşhaş (2014), yaptıkları araştırmada kaliteli bir çalgının çalışma isteğinde artış meydana getirebileceğini ifade etmişlerdir (s. 68). Çalgının iyi bir işçilikle ve doğru ayarlarla yapıldığının en temel göstergelerinden birisi de entonasyonudur. Entonasyon çalgıda notaların doğru tonda verilmesidir. İcracının yetenek ve kapasitesinin yanında, çalgının tel boyunun doğru ayarlanması entonasyona doğrudan etki etmektedir. Şişman (2010), araştırması sonucunda standart boyutta ve iyi kalitede bir çalgının entonasyon konusunda çalıcının işini kolaylaştıracağını belirtmiştir (s. 67).

Yaylı çalgı icracıları arasında yaygın olan inanışlardan birisi bir çalgı ne kadar eskiyse o kadar iyi sese sahip olacağı ve zengin tonalite sunacağıdır. Bu tamamen doğru değildir. Bir çalgının iyi ses vermesindeki temel ölçütler iyi kalite ve uyumlu ağaç seçimi, iyi işçilik ve doğru cila formülasyonu ve uygulamasıdır. Bunun üzerine yıllanan çalgının ağacı daha kuru ve gevrek hale gelecek, cilası kemikleşecek ve hem gövde hem cila düzenli çalınan çalgının titreşimlerine zaman içinde uyum sağlayarak aranan rezonans karakterini ortaya koyacaktır. Çalgı yıllandıkça ses karakteri yumuşayıp, kadifeleşecektir. Ancak tüm bu gelişmelerle birlikte, buradan eski çalgıların hep iyi ses vereceği ya da yeni çalgıların vasat ses vereceği anlamı çıkarılmamalıdır. Bu konuyla ilgili çeşitli çalışmalar vardır. Dünnwald (1991); kendisinden sonra pek çok çalışmaya temel olmuş "Deduction of Objective Quality Parameters on Old and New Violins" adlı çalışmasında, kemanda iyi ses karakteri için ideal frekans aralıklarını aramış ve çeşitli yaş ve kalitede 700 farklı kemanın akustik testlerini yaparak çalgı kaliteleri ile ses kaliteleri arasındaki ilişkiyi incelemiştir. Bu amaçla; 53 eski İtalyan çalgısı, 75 Klotz, Stainer gibi ünlü eski yapımcıların kemanı, 300 1800'ler sonrası yaşayan ünlü yapımcıların kemanı, yaklaşık 180 fabrikasyon keman, 42 amatör lutiye tarafından yapılmış keman ve birkaç diğer kemanla 700 civarı çalgı kullanmıştır. Eski İtalyan çalgılarının \% 92,5'inin, amatör yapımcıların kemanlarının \% 26,2'sinin, 1800'ler öncesi yaşayan usta yapımcıların kemanlarının \% 30,7'sinin, 1800'ler sonrası yaşayan usta yapımcılarının kemanlarının \% 19,1'inin, fabrikasyon kemanlardan 
\% 8,4'ünün çok iyi ses verdiğini belirlemiştir. Ayrıca eski İtalyan çalgılarının sadece eski oldukları için başarılı olmadıklarını, bu çalgıların yapımcılarının deneyimleri sayesinde gerçek anlamda iyi yapılmış oldukları için başarılı olduklarını ortaya koymuştur. Çünkü bu testle pek çok eski olup da iyi ses vermeyen ya da daha yeni olan ama iyi ses verebilen çalgının olduğunu göstermiştir. Dünnwald'a göre eski İtalyan yapımcılarının çalgılarının iyi ses vermesindeki en büyük nedenlerden birisi, çalgı yapımı konusundaki bilgileridir. Bu bilgi o dönemde Avrupa'daki diğer yapımcılara da aktarılmıştır. Ancak 1800'lere kadar İtalya dışındaki bölgelerde yapılan çalgılar arasında çok iyi ses verenlerin sayısı hala yüksekken, sonraki yıllarda bu bilgi birikimi zamanla kaybolmuş ve iyi ses veren kemanların sayısında bir azalma olmuştur. (s. 1-10). Bu önemli çalışma yeni yapılan çalgıların da çok iyi seviyede ses verebileceğini göstermektedir.

Konuyla ilgili yapılan diğer benzer çalışmalar da icracıların, çalgılara bakış açısıyla ilgilidir. Fritz, Curtin, Poitevineau vd. (2012), eski ünlü çalgıların, sadece eski oldukları için icracılar üzerinde psikolojik olarak iyi ses vereceği düşüncesi yaratıp yaratmadığını belirlemek için profesyonel ve amatör seviye keman icracılarına gözleri bağlı şekilde art arda farklı çalgıları çaldırmış ve hangisinin en iyisi olduklarını sormuşlardır. Çalışmada Stradivari, Guarneri Del Gesu gibi ünlü İtalyan yapımcılarının kemanlarının yanı sıra, çok yakın tarihte yapılmış iyi kalite kemanlar da kullanılmıştır. Farklı seviye icracılardan oluşan ilk çalışma, icracıların eski ve modern çalgıların hangisinin yeni, hangisinin eski olduğu konusunda tahminlerinin çoğunlukla yanlış çıktığını göstermiştir. En beğenilen keman yeni üretim bir kemanken, en az beğenilen keman bir Stradivari keman çıkmıştır. $\mathrm{Bu}$ değerlendirmeler çalgının tonalitesi, çalım rahatlığı, ataklığı ve projeksiyonu üzerinden yapılmıştır (s. 761). Yaptıkları ikinci çalışmada (2014) ise, tamamı profesyonel icracılara aynı test yapılmış, yine 6 eski İtalyan ve 6 yeni iyi kalite keman icracılara gözleri kapalı olarak çaldırılmıştır. Bu çalışma sonucunda da icracıların eski ve modern çalgıların hangisinin yeni, hangisinin eski olduğu konusundaki tahminleri çoğunlukla yanlış çıkmıştır. Tek bir modern keman tüm solistlerce en iyi ses veren olarak seçilmiştir. Bu değerlendirmeler çalgının çalım rahatlığı, projeksiyon, ses şiddeti, ton kalitesi, ses açıklı̆̆ ve genel icracı tercihi üzerinden yapılmıştır (ss. 7224-7229).

Bu çalışmalar göstermektedir ki çalgının ses kalitesi ile yaşı arasında her zaman bir doğru orantı yoktur. İcracılar hangi çalgıyı çaldıklarını bilmeden objektif olarak değerlendirme yaptıklarında, Stradivari çalgılar bile listelerde en sonlarda yer bulabilmektedirler. Tüm bunlar, yaylı çalgı ailesinde başarılı ses almanın çok kompleks bir çalışma gerektir- 
mesiyle ilişkilidir. Yapımcının bilgisi, deneyimi, işçilik kalitesi, ağaçlar, kullanılan cila tipi ve formülasyonu, doğru reglaj ve uygun tel seçimi ile çalgının yıllanmışlığı hep birlikte sese, tona, entonasyona farklı oranlarda etki etmektedir.

$\mathrm{Bu}$ araştırmada; müzik enstrümanlarının değerlendirilmesinde kullanılan alışılageldik yöntemlerden farklı olarak, son yıllarda performans değerlendirme konusunda öne çıan rubrik metodu ile enstrümanlar arası ses ve tonal farkl111kların nesnel olarak ortaya konulması hedeflenmiştir. Ürün ya da süreçleri değerlendirmede kullanılan rubrik, öznel ve otantik (özgün/gerçek) değerlendirmeler için kullanılabilen bir puanlama yöntemidir. Öznel değerlendirmelerde belirli bir düzeyde nesnellik (objektiflik) yaratılmasına yardimci olur (Anonim, 2017).

Popham (1997), rubriği, öğrenci performansının farklı boyut ve düzeylere bölünerek değerlendirilmesinde kullanılan bir puanlama anahtarı olarak tanımlar. Sözlü, yazılı sunumlar ve bilimsel projelerin değerlendirilmesinde sıklıkla kullanılabilir. Temel olarak bir soru listesi olan rubriğin üç temel özelliği vardır: değerlendirme ölçütleri, ölçüt tanımları ve puanlama stratejisi (s. 72).

Rubrik; ölçütlerden ve performans düzeylerinden oluşan yapısı ile puanlama sırasında oluşabilecek yanlılıkları en aza indirgerken, performansla ilgili daha gerçekçi ve ayrıntılı geri bildirim verme olanağı sağlar. İyi tanımlanmış bir rubrik, puanlamadan kaynaklanabilecek güvenirlik problemlerini ortadan kaldırır (Parlak ve Doğan, 2014, s. 190).

\section{Yöntem}

\section{Araştırma Yöntemi ve Modeli}

Araştırma nicel araştırma yöntemine dayalı betimsel bir çalışmadır. Araştırma modeli çalgı niteliği değerlendirmesinde rubrik kullanımı üzerinedir. Çalgı değerlendirmesinde kullanılacak ölçütler hakkında konservatuvarda 10 yılı aşkın süredir eğitimcilik yapan uzmanlardan görüş alınmıştır. Nicel bilgiler çello sanat dalı öğretim elemanlarına uygulanan "Yaylı Çalg1 Değerlendirme Rubriği”" (YÇR) ile elde edilmiştir.

\section{Çalışma Grubu}

Araştırmanın çalışma grubunu; Orta Anadolu'da bir devlet üniversitesinin devlet konservatuvarı müzik bölümü çello sanat dalından, alanında en az 10 yıllık deneyime sahip olma kriterini sağlayan altı uzman öğretim elemanı ve bir gönüllü lisans öğrencisi oluş- 
turmaktadır. Buna ek olarak akustik niteliklerini ortaya çıkarmak ve aralarında kıyaslama yapmak amacıyla üç farklı el yapımı çello kullanılmıştır.

Tablo 1. Araştırmada kullanılan çelloların listesi

\begin{tabular}{|l|c|c|}
\hline \multicolumn{1}{|c|}{ Yapımcı } & Yapım Yılı & Boy \\
\hline 1 Numaralı Türk Yapımcı & 2016 & $4 / 4$ \\
\hline 2 Numaralı Türk Yapımcı & 2016 & $4 / 4$ \\
\hline Fransız Yapımcı & 1950 & $4 / 4$ \\
\hline
\end{tabular}

\section{Verilerin Toplanması}

Daha önceden belirtildiği üzere, araştırmada devlet konservatuvarı öğretim elemanlarından altı uzman ile yaylı çalgılar anasanat dalında öğrenim gören lisans öğrencilerinden bir gönüllü öğrenci yer almıştır. Rubrik kriterlerinin belirlenmesi amacıyla uzman görüşleri toplanmıştır. Değerlendirme ölçütleri uzman görüşleri alınarak; çalgıların Pianissimo (PP) ve Piano (PP) Ses Üretme Becerisi, Fortissimo (FF) ve Forte (F) Ses Üretme Becerisi, Ses Rengi Çeşitliliği, Vibrato Üretimi, Sesin Farklı Registerlerdeki (tuşenin farklı bölgelerindeki) Gürlük Eşitliği, Sesin Farklı Tellerdeki Gürlük Eşitliği, Özgün Ses Tonu olarak belirlenmiştir. "PP ve P Ölçütü” çalgının çok hafif çalma becerisinin seviyesini ifade eder. "FF ve F Ölçütü" çalgının çok güçlü çalma becerisinin seviyesini ifade eder. "Ses Rengi Çeşitliliği Ölçütü" çalgının sesinin ne kadar zengin ve kompleks olduğunu ifade eder. "Vibrato Üretimi" çalgının tüm teller ve seslerdeki vibrato üretim seviyesini ifade eder. "Ses Gürlüğü Ölçütleri” çalgının farklı teller veya tuşenin farklı bölgelerindeki ses şiddetinin dengesini ifade eder. Son olarak "Özgün Ses Tonu Ölçütü” çalgıların özgün ses tonlarının estetik olarak ne kadar iyi olduğunu ifade eder. Her ölçüt beş puanlık ölçekte çok iyi (5), iyi (4), orta (3), zayıf (2) ve çok zayıf (1) olarak değerlendirilmiştir. Çalışmanın "Bulgular ve Yorumlar" kısmında her bir ölçütün rubrik seviye tanımları da yapılmıştır. Bu ölçütleri değerlendirmek amacıyla seslendirilecek uygun parçalar repertuvardan yine alan uzmanlarıyla birlikte belirlenmiştir. Sonrasında araştırmada yer alacak öğrenci temel çello repertuvarından seçilmiş parçaları bireysel olarak çalışmıştır. Bu sürecin ardından öğrenciden performansını üç farklı el yapımı çello ile sergilemesi istenmiştir. Öğrencinin farklı çalgılarla ortaya koyduğu performansın uzmanlarca gözlemlenmesi ve incelenmesi amacıyla video kaydı yapılmıştır. Süreç boyunca çalgılar "Çello 1", "Çello 2", "Çello 3" şeklinde kodlanmış ve değerlendiricilere çalgı veya yapımcının isim bilgisi verilmemiştir. Son olarak uzmanlar, üç çalgının ses niteliklerini belirlenmiş yedi ölçüt üzerinden değerlendirmiştir. Çalgıların performansları ara- 
sında ortaya çıkan farklara dayalı olarak elde edilen bulgular uzmanlar ve araştırmacılarca tartışılmıştır.

\section{Verilerin Çözümlenmesi ve Yorumlanması}

"Yaylı Çalgı Değerlendirme Rubriği” (YÇR) ile elde edilen nicel veriler SPSS 20 (Statistical Package for the Social Sciences) veri işleme yazılımıyla çözümlenmiştir.

Rubrik üzerindeki farklı görüşleri karşılaştırmak için tanımlayıcı analizler (frekans, yüzde, toplam puan, ağırlıklı toplam) yapılmıştır. Bulgular tablolaştırılıp, grafiğe dökülerek değerlendirilmiştir.

\section{Bulgular ve Yorumlar}

Bu bölümde, uzman görüşlerine dayalı olarak, konuya ilişkin öğretim elemanlarına uygulanan "Yaylı Çalgı Değerlendirme Rubriği”"nden (YÇR) elde edilen sonuçlar tablolaştırılarak yorumlanmıştır. Tüm değerlendirmelerde kullanılan çello sıralaması aşağıdaki gibidir:

Çello 1 - Türk Yapımc1 2016 yapımı

Çello 2 - Türk Yapımcı 2016 yapımı

Çello 3 - Fransız Yapımc1 1950 yapımı

Tablo 2. YÇR Pianissimo ve Piano Ses Üretme Ölçütü

\begin{tabular}{|c|c|c|c|c|c|}
\hline & $\begin{array}{c}\text { Çok iyi } \\
\text { (5 puan) }\end{array}$ & $\begin{array}{c}\text { İyi } \\
\text { (4 puan) }\end{array}$ & $\begin{array}{c}\text { Orta } \\
(3 \text { puan })\end{array}$ & $\begin{array}{c}\text { Zayıf } \\
(2 \text { puan })\end{array}$ & $\begin{array}{l}\text { Çok Zayıf } \\
\text { (1 Puan) }\end{array}$ \\
\hline $\begin{array}{l}\text { PP ve P Ses } \\
\text { Üretme Becerisi }\end{array}$ & $\begin{array}{l}\text { Çalgının çok } \\
\text { hafif çalma } \\
\text { becerisinin en } \\
\text { yüksek seviyede } \\
\text { olduğunu ifade } \\
\text { eder. }\end{array}$ & $\begin{array}{l}\text { Çalgının çok } \\
\text { hafif çalma } \\
\text { becerisinin } \\
\text { iyi seviyede } \\
\text { olduğunu ifade } \\
\text { eder. }\end{array}$ & $\begin{array}{l}\text { Çalgının çok } \\
\text { hafif çalma } \\
\text { becerisinin } \\
\text { orta seviyede } \\
\text { olduğunu ifade } \\
\text { eder. }\end{array}$ & $\begin{array}{l}\text { Çalgının çok } \\
\text { hafif çalma } \\
\text { becerisinin } \\
\text { zayıf seviyede } \\
\text { olduğunu ifade } \\
\text { eder. }\end{array}$ & $\begin{array}{l}\text { Çalgının çok } \\
\text { hafif çalma } \\
\text { becerisinin çok } \\
\text { zayıf seviyede } \\
\text { olduğunu ifade } \\
\text { eder. }\end{array}$ \\
\hline
\end{tabular}

Tablo 3. Pianissimo ve piano ses üretme becerisi

\begin{tabular}{|c|c|c|c|c|c|c|}
\hline Derecelendirme Ölçeği & \multicolumn{2}{|c|}{ Çello 1} & \multicolumn{2}{|c|}{ Çello 2} & \multicolumn{2}{|c|}{ Çello 3} \\
\hline & f & $\%$ & f & $\%$ & f & $\%$ \\
\hline Çok iyi & 2 & 33,3 & 3 & 50,0 & 0 & 0,0 \\
\hline İyi & 2 & 33,3 & 1 & 33,3 & 3 & 50,0 \\
\hline Orta & 1 & 16,7 & 2 & 16,7 & 2 & 33,3 \\
\hline Zayif & 1 & 16,7 & 0 & 0,0 & 1 & 16,7 \\
\hline Çok Zayıf & 0 & 0,0 & 0 & 0,0 & 0 & 0,0 \\
\hline Toplam & 6 & 100,0 & 6 & 100,0 & 6 & 100,0 \\
\hline Ağırlıklı Toplam Puan & \multicolumn{2}{|c|}{23} & \multicolumn{2}{|c|}{25} & \multicolumn{2}{|c|}{20} \\
\hline
\end{tabular}


Tablo 3'te görüldüğg̈ü üzere, çelloların pianissimo ve piano ses üretme becerilerine göre, değerlendiricilerin \% 60'indan fazlası Çello 1'i başarılı bulmuştur. Diğerleri ise orta ve zayıf olarak değerlendirmiştir. Çello 2 için değerlendiricilerin çoğu çok iyi ve iyi değerlendirmesi yapmış, sadece bir kısmı orta seviyede bulmuştur. Hiç bir katılımcı tarafından zayıf ya da çok zayıf bulunmamıştır. Çello 3'e gelindiğinde, değerlendiriciler çello 3'ü diğer iki çalgıya göre daha zayıf bulmuşlardır. Değerlendiricilerin sadece yarısı çalgıyı iyi bulmuş, kalanlar ise orta veya zayıf olarak değerlendirmiş̧tir. Bu ölçütte değerlendiriciler hiç bir çelloyu çok zayıf olarak görmemiştir.

Elde edilen bu bulgulara göre değerlendiriciler; çalgıların pianissimo ve piano ses üretme becerileri anlamında en başarılısı olarak Çello 2'yi, sonrasında Çello 1'i ve en az başarılı olarak Çello 3'ü bulmuşlardır.

Tablo 4. YÇR Fortissimo ve Forte Ses Üretme Ölçütü

\begin{tabular}{|c|c|c|c|c|c|}
\hline & $\begin{array}{c}\text { Çok iyi } \\
\text { (5 puan) }\end{array}$ & $\begin{array}{c}\text { İyi } \\
\text { (4 puan) }\end{array}$ & $\begin{array}{c}\text { Orta } \\
\text { (3 puan) }\end{array}$ & $\begin{array}{c}\text { Zayif } \\
\text { (2 puan) }\end{array}$ & $\begin{array}{l}\text { Çok Zayıf } \\
\text { (1 Puan) }\end{array}$ \\
\hline $\begin{array}{l}\text { FF ve F Ses } \\
\text { Üretme Becerisi }\end{array}$ & $\begin{array}{l}\text { Çalgının çok } \\
\text { güçlü çalma } \\
\text { becerisinin en } \\
\text { yüksek seviyede } \\
\text { olduğunu ifade } \\
\text { eder. }\end{array}$ & $\begin{array}{l}\text { Çalgının çok } \\
\text { güçlü çalma } \\
\text { becerisinin } \\
\text { iyi seviyede } \\
\text { olduğunu ifade } \\
\text { eder. }\end{array}$ & $\begin{array}{l}\text { Çalgının çok } \\
\text { güçlü çalma } \\
\text { becerisinin } \\
\text { orta seviyede } \\
\text { olduğunu ifade } \\
\text { eder. }\end{array}$ & $\begin{array}{l}\text { Çalgının çok } \\
\text { güçlü çalma } \\
\text { becerisinin } \\
\text { zayıf seviyede } \\
\text { olduğunu ifade } \\
\text { eder. }\end{array}$ & $\begin{array}{l}\text { Çalginın çok } \\
\text { güçlü çalma } \\
\text { becerisinin çok } \\
\text { zayıf seviyede } \\
\text { olduğunu ifade } \\
\text { eder. }\end{array}$ \\
\hline
\end{tabular}

Tablo 5. Fortissimo ve forte ses üretme becerisi

\begin{tabular}{|l|c|c|c|c|c|c|}
\hline Derecelendirme Ölçeği & \multicolumn{2}{|c|}{ Çello 1 } & \multicolumn{2}{c|}{ Çello 2 } & \multicolumn{2}{c|}{ Çello 3 } \\
\hline & f & \% & f & \% & f & \% \\
\hline Çok iyi & 0 & 0,0 & 1 & 16,7 & 0 & 0,0 \\
\hline İyi & 4 & 66,6 & 3 & 50,0 & 3 & 50,0 \\
\hline Orta & 1 & 16,7 & 2 & 33,3 & 3 & 50,0 \\
\hline Zayıf & 1 & 16,7 & 0 & 0,0 & 0 & 0,0 \\
\hline Çok Zayıf & 0 & 0,0 & 0 & 0,0 & 0 & 0,0 \\
\hline \multicolumn{1}{r|r|r|r|r|}{ Toplam } & 6 & 100,0 & 6 & 100,0 & 6 & 100,0 \\
\hline \multicolumn{1}{|c|}{ Ağırlıkı Toplam Puan } & 21 & \multicolumn{3}{|c|}{23} & \multicolumn{3}{c|}{21} \\
\hline
\end{tabular}

Tablo 5 'te görüldüğ̈̈ üzere, çelloların fortissimo ve forte ses üretme becerilerine göre, değerlendiricilerin \% 60'ından fazlası Çello 1'i başarılı bulmuştur. Diğerleri ise orta ve zayıf olarak değerlendirmiştir. Biraz daha iyi performans göstermiş olan Çello 2 için değerlendiricilerin \% 60'ından fazlası çok iyi ve iyi değerlendirmesi yapmış, kalan üçte birlik kesim ise orta seviyede bulmuştur. Çello 3'e gelindiğinde değerlendiricilerin yar1s1 iyi, yarısı orta düzeyde başarılı bulmuşlardır. Uzmanlar f ve ff ölçütüne göre hiç bir çellonun çok zayıf olmadığında hemfikir olmuşlardır. 
Elde edilen bu bulgulara göre değerlendiriciler; çalgıların fortissimo ve forte ses üretme niteliği anlamında en başarılısı olarak Çello 2'yi, sonrasında Çello 1'i ve Çello 3'ü eşit düzeyde bulmuşlardır.

Tablo 6. YÇR Ses Rengi Çeşitliliği Ölçütü

\begin{tabular}{|c|c|c|c|c|c|}
\hline & $\begin{array}{l}\text { Çok iyi } \\
\text { (5 puan) }\end{array}$ & $\begin{array}{c}\text { İyi } \\
\text { (4 puan) }\end{array}$ & $\begin{array}{c}\text { Orta } \\
(3 \text { puan })\end{array}$ & $\begin{array}{c}\text { Zayıf } \\
\text { (2 puan) }\end{array}$ & $\begin{array}{l}\text { Çok Zayıf } \\
\text { (1 Puan) }\end{array}$ \\
\hline $\begin{array}{l}\text { Ses Renklerinin } \\
\text { Çeşitliliği }\end{array}$ & $\begin{array}{c}\text { Çalgının } \\
\text { tüm teller ve } \\
\text { seslerde tonalite } \\
\text { zenginliğinin en } \\
\text { yüksek seviyede } \\
\text { olduğunu ifade } \\
\text { eder. }\end{array}$ & $\begin{array}{c}\text { Çalgının } \\
\text { tüm teller ve } \\
\text { seslerde tonalite } \\
\text { zenginliğinin } \\
\text { iyi seviyede } \\
\text { olduğunu ifade } \\
\text { eder. }\end{array}$ & $\begin{array}{c}\text { Çalgının } \\
\text { tüm teller ve } \\
\text { seslerde tonalite } \\
\text { zenginliğinin } \\
\text { orta seviyede } \\
\text { olduğunu ifade } \\
\text { eder. }\end{array}$ & $\begin{array}{c}\text { Çalgının } \\
\text { tüm teller ve } \\
\text { seslerde tonalite } \\
\text { zenginliğinin } \\
\text { zayıf seviyede } \\
\text { olduğunu ifade } \\
\text { eder. }\end{array}$ & $\begin{array}{c}\text { Çalgının } \\
\text { tüm teller ve } \\
\text { seslerde tonalite } \\
\text { zenginliğinin çok } \\
\text { zayıf seviyede } \\
\text { olduğunu ifade } \\
\text { eder. }\end{array}$ \\
\hline
\end{tabular}

Tablo 7. Ses renklerinin çeşitliliği

\begin{tabular}{|l|c|c|c|c|c|c|}
\hline Derecelendirme Ölçeği & \multicolumn{2}{|c|}{ Çello 1 } & \multicolumn{2}{c|}{ Çello 2 } & \multicolumn{2}{c|}{ Çello 3 } \\
\hline & f & \% & f & \% & f & \% \\
\hline Çok iyi & 0 & 0,0 & 1 & 16,7 & 1 & 16,7 \\
\hline İyi & 2 & 33,3 & 3 & 50,0 & 3 & 50,0 \\
\hline Orta & 3 & 50,0 & 2 & 33,3 & 2 & 33,3 \\
\hline Zayıf & 1 & 16,7 & 0 & 0,0 & 0 & 0,0 \\
\hline Çok Zayıf & 0 & 0,0 & 0 & 0,0 & 0 & 0,0 \\
\hline \multicolumn{1}{|c|}{ Toplam } & 6 & 100,0 & 6 & 100,0 & 6 & 100,0 \\
\hline \multicolumn{2}{|c|}{19} & \multicolumn{3}{|c|}{23} & \multicolumn{2}{c|}{23} \\
\hline
\end{tabular}

Tablo 7'de görüldüğü üzere, çelloların ses renklerinin çeşitliliği ölçütünde Çello 1, diğerlerinden daha az başarılı olmuştur. Değerlendiricilerin yarısı çalgıyı bu ölçütte orta seviyede bulmuş, sadece üçte biri iyi bulmuş, kalanları da zayıf olarak bulmuştur. Belirgin şekilde daha iyi performans gösteren Çello 2 ise değerlendiricilerin \% 60' 1 ndan fazlasınca iyi ve çok iyi olarak bulunmuş, kalan üçte birlik kesime göre de orta düzeyde başarılı bulunmuştur. Aynı sonuçlara sahip olan Çello 3 yine benzer şekilde iyi performans göstermiştir. Değerlendiriciler, bu ölçütte hiç bir çalgıyı çok zayıf bulmamışlardır.

Elde edilen bu bulgulara göre değerlendiriciler; çalgıların ses renklerinin çeşitliliği anlamında Çello 2 ve Çello 3'ü eşit derecede iyi, sonrasında Çello 1'i başarılı bulmuşlardir. 
Tablo 8 YÇR Vibrato Üretme Ölçütleri

\begin{tabular}{|c|c|c|c|c|c|}
\hline & $\begin{array}{c}\text { Çok iyi } \\
\text { (5 puan) }\end{array}$ & $\begin{array}{c}\text { İyi } \\
\text { (4 puan) }\end{array}$ & $\begin{array}{c}\text { Orta } \\
\text { (3 puan) }\end{array}$ & $\begin{array}{c}\text { Zayıf } \\
(2 \text { puan })\end{array}$ & $\begin{array}{c}\text { Çok Zayıf } \\
\text { (1 Puan) }\end{array}$ \\
\hline Vibrato Üretimi & $\begin{array}{c}\text { Çalgının } \\
\text { tüm teller ve } \\
\text { seslerde ürettiği } \\
\text { vibratonun } \\
\text { zenginliğinin en } \\
\text { yüksek seviyede } \\
\text { olduğunu ifade } \\
\text { eder. }\end{array}$ & $\begin{array}{c}\text { Çalgının } \\
\text { tüm teller ve } \\
\text { seslerde ürettiği } \\
\text { vibratonun } \\
\text { zenginliğinin } \\
\text { iyi seviyede } \\
\text { olduğunu ifade } \\
\text { eder. }\end{array}$ & $\begin{array}{c}\text { Çalgının } \\
\text { tüm teller ve } \\
\text { seslerde ürettiği } \\
\text { vibratonun } \\
\text { zenginliğinin } \\
\text { orta seviyede } \\
\text { olduğunu ifade } \\
\text { eder. }\end{array}$ & $\begin{array}{c}\text { Çalgının } \\
\text { tüm teller ve } \\
\text { seslerde ürettiği } \\
\text { vibratonun } \\
\text { zenginliğinin } \\
\text { zayıf seviyede } \\
\text { olduğunu ifade } \\
\text { eder. }\end{array}$ & $\begin{array}{c}\text { Çalgının } \\
\text { tüm teller ve } \\
\text { seslerde ürettiği } \\
\text { vibratonun } \\
\text { zenginliğinin çok } \\
\text { zayıf seviyede } \\
\text { olduğunu ifade } \\
\text { eder. }\end{array}$ \\
\hline
\end{tabular}

Tablo 9. Vibrato üretme becerisi

\begin{tabular}{|c|c|c|c|c|c|c|}
\hline \multirow[t]{2}{*}{ Derecelendirme Ölçeği } & \multicolumn{2}{|c|}{ Çello 1} & \multicolumn{2}{|c|}{ Çello 2} & \multicolumn{2}{|c|}{ Çello 3} \\
\hline & f & $\%$ & f & $\%$ & f & $\%$ \\
\hline Çok iyi & 2 & 33,3 & 3 & 50,0 & 1 & 16,7 \\
\hline İyi & 3 & 50,0 & 2 & 33,3 & 2 & 33,3 \\
\hline Orta & 1 & 16,7 & 1 & 16,7 & 2 & 33,3 \\
\hline Zayif & 0 & 0,0 & 0 & 0,0 & 1 & 16,7 \\
\hline Çok Zayıf & 0 & 0,0 & 0 & 0,0 & 0 & 0,0 \\
\hline $\begin{array}{c}\text { Toplam } \\
\end{array}$ & 6 & 100,0 & 6 & 100,0 & 6 & 100,0 \\
\hline Ağırlıklı Toplam Puan & \multicolumn{2}{|c|}{25} & \multicolumn{2}{|c|}{26} & \multicolumn{2}{|c|}{21} \\
\hline
\end{tabular}

Tablo 9'da görüldüğü üzere, çelloların vibrato üretim becerilerine göre, Çello 1 çok iyi performans göstermiştir. Değerlendiricilerin \%80'inden fazlası çalgıyı iyi ve çok iyi bulmuş, sadece az sayıda katılımcı orta düzeyde bulmuştur. Oldukça yakın sonuçlar Çello 2 için de elde edilmiştir, ancak bu çalg1, Çello 1'den de iyi performans göstermiştir. Çello 3 için ise katılımcılar bölünmüş durumdadır. Çoğu orta ya da iyi değerlendirmesi yapmış, ancak kalanların bir kısmı çok iyi değerlendirmesi yaparken, bir kısmı ise zayıf değerlendirmesi yapmıştır. Bu ölçütte hiç bir çalgı çok zayıf olarak değerlendirilmemiştir.

Elde edilen bu bulgulara göre değerlendiriciler; çalgıların vibrato üretimi anlamında en başarılısı olarak Çello 2'yi, sonrasında Çello 1'i ve en az başarılı olarak da Çello 3'ü bulmuşlardır. 
Tablo 10. YÇR Sesin Farklı Registerlerde Gürlük Eşitliği Ölçütü

\begin{tabular}{|l|c|c|c|c|c|}
\hline & $\begin{array}{c}\text { Çok iyi } \\
\text { (5 puan) }\end{array}$ & $\begin{array}{c}\text { İyi } \\
\text { (4 puan) }\end{array}$ & $\begin{array}{c}\text { Orta } \\
\text { (3 puan) }\end{array}$ & $\begin{array}{c}\text { Zayıf } \\
\text { (2 puan) }\end{array}$ & $\begin{array}{c}\text { Çok Zayıf } \\
\text { (1 Puan) }\end{array}$ \\
\hline & Çalgının çok & Çalgının çok & Çalgının çok & Çalgııın çok & Çalgının çok \\
gesin Farklü ve çok & güçlü ve çok & güçlü ve çok & güçlü ve çok & güçlü ve çok \\
hafif çalma çalma & hafif çalma \\
Registerlerde & hafif çalma & hafif çalma & hafif & becerisinin & becerisinin her \\
(tuşenin farklı & becerisinin her & becerisinin & becerisinin & her \\
bölgelerinde) & registerde en & her registerde & her registerde & her registerde & registerde çok \\
Gürlük Eşitliği & yüksek seviyede & iyi seviyede & orta seviyede & zayıf seviyede & zayıf seviyede \\
& olduğunu ifade & olduğunu ifade & olduğunu ifade & olduğunu ifade & olduğunu ifade \\
& eder. & eder. & eder. & eder. & eder. \\
\hline
\end{tabular}

Tablo 11. Farklı registerlerde gürlük eşitliği becerisi

\begin{tabular}{|c|c|c|c|c|c|c|}
\hline Derecelendirme Ölçeği & \multicolumn{2}{|c|}{ Çello 1} & \multicolumn{2}{|c|}{ Çello 2} & \multicolumn{2}{|c|}{ Çello 3} \\
\hline & f & $\%$ & f & $\%$ & f & $\%$ \\
\hline Çok iyi & 0 & 0 & 0 & 0 & 0 & 0 \\
\hline İyi & 3 & 50,0 & 5 & 83,3 & 4 & 66,7 \\
\hline Orta & 3 & 50,0 & 1 & 16,7 & 2 & 33,3 \\
\hline Zayif & 0 & 0 & 0 & 0 & 0 & 0 \\
\hline Çok Zayıf & 0 & 0 & 0 & 0 & 0 & 0 \\
\hline Toplam & 6 & 100,0 & 6 & 100,0 & 6 & 100,0 \\
\hline Ağırlıklı Toplam Puan & \multicolumn{2}{|c|}{21} & \multicolumn{2}{|c|}{23} & \multicolumn{2}{|c|}{22} \\
\hline
\end{tabular}

Tablo 11'de görüldüğü üzere, çelloların sesin farklı registerlerdeki gürlük eşitliği becerilerine göre, Çello 1 için katılımcıların yarısı iyi, diğer yarısı orta değerlendirmesi yapmıştır. Biraz daha iyi performans göstermiş olan Çello 2 için katılımcıların \%80'inden fazlası iyi, kalanları ise orta değerlendirmesi yapmıştır. Benzer sonuçlar elde eden Çello 3 için, değerlendirenlerin \% 60'1ndan fazlası iyi, kalan üçte birlik kesim ise orta değerlendirmesi yapmıştır.

Elde edilen bu bulgulara göre değerlendiriciler; çalgıların sesin farklı registerlerdeki gürlük eşitliği anlamında en başarılısı olarak Çello 2'yi, sonrasında Çello 3'ü ve en az başarılı olarak da Çello 1'i bulmuşlardır. 
Tablo 12. YÇR Sesin Farklı Tellerdeki Gürlük Eşitliği Ölçütü

\begin{tabular}{|c|c|c|c|c|c|}
\hline & $\begin{array}{c}\text { Çok iyi } \\
\text { (5 puan) }\end{array}$ & $\begin{array}{c}\text { İyi } \\
\text { (4 puan) }\end{array}$ & $\begin{array}{c}\text { Orta } \\
(3 \text { puan) }\end{array}$ & $\begin{array}{c}\text { Zayıf } \\
\text { (2 puan) }\end{array}$ & $\begin{array}{l}\text { Çok Zayıf } \\
\text { (1 Puan) }\end{array}$ \\
\hline $\begin{array}{l}\text { Sesin Farklı } \\
\text { Tellerdeki } \\
\text { Gürlük Eşitliğgi }\end{array}$ & $\begin{array}{l}\text { Çalgının çok } \\
\text { güçlü ve çok } \\
\text { hafif çalma } \\
\text { becerisinin } \\
\text { farklı tellerde en } \\
\text { yüksek seviyede } \\
\text { olduğunu ifade } \\
\text { eder. }\end{array}$ & $\begin{array}{l}\text { Çalgıının çok } \\
\text { güçlü ve çok } \\
\text { hafif çalma } \\
\text { becerisinin } \\
\text { farklı tellerde } \\
\text { iyi seviyede } \\
\text { olduğunu ifade } \\
\text { eder. }\end{array}$ & $\begin{array}{l}\text { Çalgının çok } \\
\text { güçlü ve çok } \\
\text { hafif çalma } \\
\text { becerisinin } \\
\text { farklı tellerde } \\
\text { orta seviyede } \\
\text { olduğunu ifade } \\
\text { eder. }\end{array}$ & $\begin{array}{l}\text { Çalgının çok } \\
\text { güçlü ve çok } \\
\text { hafif çalma } \\
\text { becerisinin } \\
\text { farklı tellerde } \\
\text { zayıf seviyede } \\
\text { olduğunu ifade } \\
\text { eder. }\end{array}$ & $\begin{array}{l}\text { Çalgının çok } \\
\text { güçlü ve çok } \\
\text { hafif çalma } \\
\text { becerisinin farkl } \\
\text { tellerde çok } \\
\text { zayıf seviyede } \\
\text { olduğunu ifade } \\
\text { eder. }\end{array}$ \\
\hline
\end{tabular}

Tablo 13. Farklı tellerde gürlük eşitliği becerisi

\begin{tabular}{|c|c|c|c|c|c|c|}
\hline Derecelendirme Ölçeği & \multicolumn{2}{|c|}{ Çello 1} & \multicolumn{2}{|c|}{ Çello 2} & \multicolumn{2}{|c|}{ Çello 3} \\
\hline & f & $\%$ & $\mathbf{f}$ & $\%$ & f & $\%$ \\
\hline Çok iyi & 0 & 0 & 0 & 0 & 0 & 0 \\
\hline İyi & 2 & 33,3 & 4 & 66,7 & 5 & 83,3 \\
\hline Orta & 4 & 66,7 & 2 & 33,3 & 1 & 16,7 \\
\hline Zayif & 0 & 0 & 0 & 0 & 0 & 0 \\
\hline Çok Zayıf & 0 & 0 & 0 & 0 & 0 & 0 \\
\hline $\begin{array}{l}\text { Toplam } \\
\end{array}$ & 6 & 100,0 & 6 & 100,0 & 6 & 100,0 \\
\hline Ağırlıkı Toplam Puan & \multicolumn{2}{|c|}{20} & \multicolumn{2}{|c|}{22} & \multicolumn{2}{|c|}{23} \\
\hline
\end{tabular}

Tablo 13’te görüldüğü üzere, çelloların sesin farklı tellerdeki gürlük eşitliğine ilişkin ölçüte, Çello 1 için değerlendiricilerin \% 60'1ndan fazlası orta, kalan üçte birlik kısım iyi değerlendirmesi yapmıştır. Biraz daha iyi performans gösteren Çello 2 için ise değerlendiricilerin \% 60'ından fazlasınca iyi, kalan üçte birlik kısımca da orta değerlendirmesi yapılmıştır. Bu ölçütte en iyi performans sergilemiş olan Çello 3 için ise değerlendiricilerin \% 80'lik büyük çoğunluğu iyi değerlendirmesi yapmış, kalanlar ise orta olarak değerlendirmiştir.

Elde edilen bu bulgulara göre değerlendiriciler; çalgıların sesin farklı tellerdeki gürlük eşitliği anlamında en başarılısı olarak Çello 3'ü, sonrasında Çello 2'yi ve üçüncü olarak da Çello 1'i bulmuşlardır. 
Tablo 14. YÇR Özgün Ses Tonu Ölçütü

\begin{tabular}{|c|c|c|c|c|c|}
\hline & $\begin{array}{c}\text { Çok iyi } \\
\text { (5 puan) }\end{array}$ & $\begin{array}{c}\text { İyi } \\
\text { (4 puan) }\end{array}$ & $\begin{array}{c}\text { Orta } \\
\text { (3 puan) }\end{array}$ & $\begin{array}{c}\text { Zayıf } \\
\text { (2 puan) }\end{array}$ & $\begin{array}{l}\text { Çok Zayıf } \\
\text { (1 Puan) }\end{array}$ \\
\hline Özgün Ses Tonu & $\begin{array}{l}\text { Çalgının özgün } \\
\text { ses tonunun } \\
\text { estetik olarak en } \\
\text { yüksek seviyede } \\
\text { olduğunu ifade } \\
\text { eder. }\end{array}$ & $\begin{array}{l}\text { Çalgının özgün } \\
\text { ses tonunun } \\
\text { estetik olarak } \\
\text { iyi seviyede } \\
\text { olduğunu ifade } \\
\text { eder. }\end{array}$ & $\begin{array}{l}\text { Çalgının özgün } \\
\text { ses tonunun } \\
\text { estetik olarak } \\
\text { orta seviyede } \\
\text { olduğunu ifade } \\
\text { eder. }\end{array}$ & $\begin{array}{l}\text { Çalgının özgün } \\
\text { ses tonunun } \\
\text { estetik olarak } \\
\text { zayıf seviyede } \\
\text { olduğunu ifade } \\
\text { eder. }\end{array}$ & $\begin{array}{l}\text { Çalgının özgün } \\
\text { ses tonunun } \\
\text { estetik olarak en } \\
\text { zayıf seviyede } \\
\text { olduğunu ifade } \\
\text { eder. }\end{array}$ \\
\hline
\end{tabular}

Tablo 15. Özgün ses tonu becerileri

\begin{tabular}{|l|c|c|c|c|c|c|}
\hline Derecelendirme Ölçeği & \multicolumn{2}{|c|}{ Çello 1 } & \multicolumn{2}{c|}{ Çello 2 } & \multicolumn{2}{c|}{ Çello 3 } \\
\hline & f & \% & f & \% & f & \% \\
\hline Çok iyi & 2 & 33,3 & 0 & 0 & 2 & 33,3 \\
\hline İyi & 2 & 33,3 & 2 & 33,3 & 3 & 50,0 \\
\hline Orta & 1 & 16,7 & 4 & 66,7 & 1 & 16,7 \\
\hline Zayıf & 1 & 16,7 & 0 & 0 & 0 & 0 \\
\hline Çok Zayıf & 0 & 0 & 0 & 0 & 0 & 0 \\
\hline \multicolumn{1}{|c|}{ Toplam } & 6 & 100,0 & 6 & 100,0 & 6 & 100,0 \\
\hline \multicolumn{1}{|c|}{ Ağırlıklı Toplam Puan } & 23 & \multicolumn{3}{|c|}{20} & \multicolumn{3}{c|}{25} \\
\hline
\end{tabular}

Tablo 15'te görüldüğü üzere, çelloların özgün ses tonuna ilişkin ölçütte, Çello 1 için değerlendiriciler bölünmüşlerdir. \% 60’’ndan fazlası iyi ve çok iyi değerlendirmesi yapmıştır. Ancak kalanlar orta ve zayıf olarak bölünmüşlerdir. Daha vasat bir performans sergilemiş olan Çello 2 için değerlendiricilerin \% 60'1ndan fazlası orta değerlendirmesi yapmış, kalan üçte birlik kesim iyi değerlendirmesinde bulunmuştur. Bu ölçütte en iyi performansı sergileyen Çello 3 ise değerlendiricilerin \% 80'inden fazlası tarafından iyi ve çok iyi olarak değerlendirilmiştir. Kalan az bir kısmına göre de orta seviyede bulunmuştur. Hiçbir çello bu ölçüte göre çok zayıf bulunmamıştır.

Elde edilen bu bulgulara göre katılımcılar; çalgıların özgün ses tonu anlamında en başarılısı olarak Çello 3'ü, sonrasında Çello 1'i ve en az başarılı olarak da Çello 2'yi bulmuşlardir. 


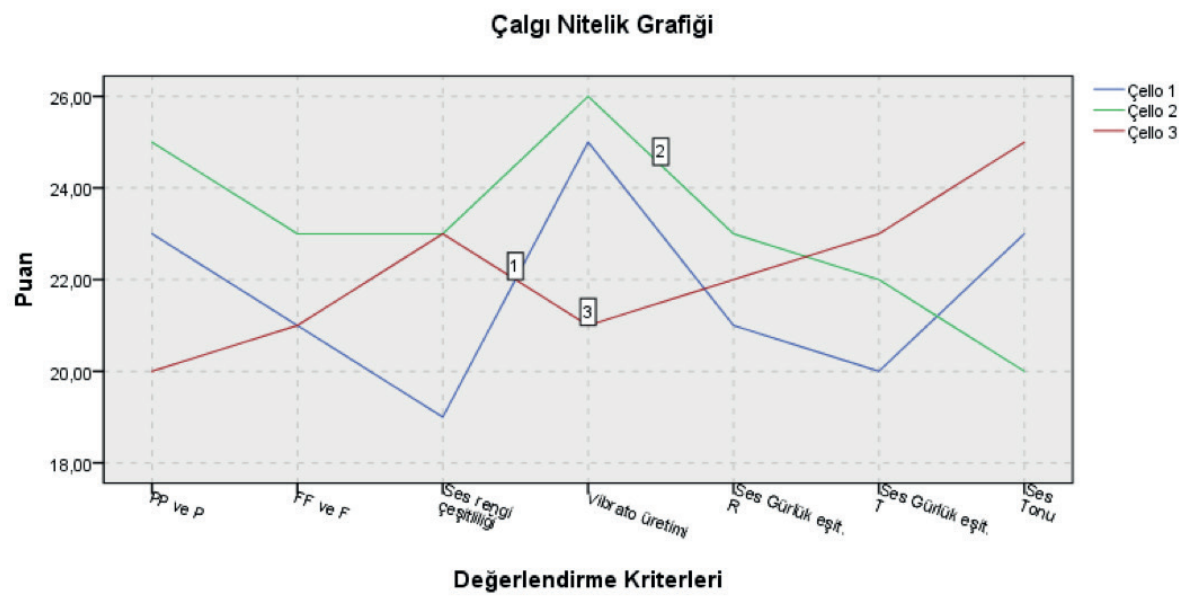

Grafik 1. Çalg1 Nitelikleri Grafiği

Grafik 1'de çalışmada kullanılan çelloların tüm ölçütlerde aldıkları ağırlıklı puanlara göre başarı durumları görülebilmektedir. Daha yeni üretim tarihli olan Çello 1 ve 2 oldukça benzer ses karakteristiğine sahiptir.

Çello 1, Çello 2'ye çok benzer özellikler sergilemiş ama genel olarak Çello 2'den daha az başarılı bulunmuştur. Farklı olarak özgün ses tonunda daha başarılı bulunmuştur. $\mathrm{Bu}$ çalgının en başarılı özelliği vibrato üretimidir. Ses rengi çeşitliliği en zayıf özelliği olan çalg1, aynı zamanda tüm çalgılar arasında bu ölçütte en başarısız olarak belirlenmiştir.

Çello 2; benzer özellikler sergilediği Çello 1'den daha başarılı bulunmuştur. Vibrato üretimi en kuvvetli özelliği olarak değerlendirilmiş olan çalg1, aynı zamanda tüm çalgılar arasında da en iyi vibrato veren çalgı olarak değerlendirilmiştir. En zayıf yönü özgün ses tonu olan çalgı, aynı zamanda tüm çalgılar arasında bu ölçütte en başarısız olarak belirlenmiştir.

İki çalgı da değerlendirme ölçütleri arasında değişken başarıya sahiptir. Pianissimo ve piano ses üretimi ile vibrato üretiminde çok başarılı iken, sesin gürlük eşitliğinde, ses rengi ve özgün ses tonunda performansları daha zayıf bulunmuştur. Başarılı ve başarısız oldukları ölçütlerin puanlarında büyük farklılıklar bulunmaktadır.

Çello 3 ise bu iki çalgıdan daha eski üretimli ve daha uzun süredir çalınan bir çalgıdır. Özgün ses tonu üretimi en kuvvetli yönü olan çalg1, aynı zamanda bu ölçütte en başarılı 
çalgı olarak değerlendirilmiştir. Pianissimo ve piano ses üretimi en zayıf yönü olan çalgı, bu ölçütte çalışmadaki en başarısız çalgı olarak belirlenmiştir. Bununla beraber Çello 3, tüm ölçütler arası daha dengeli ve istikrarlı bir ses verimine sahiptir. Başarılı ve başarısız olduğu ölçütler arası puanları birbirine yakındır.

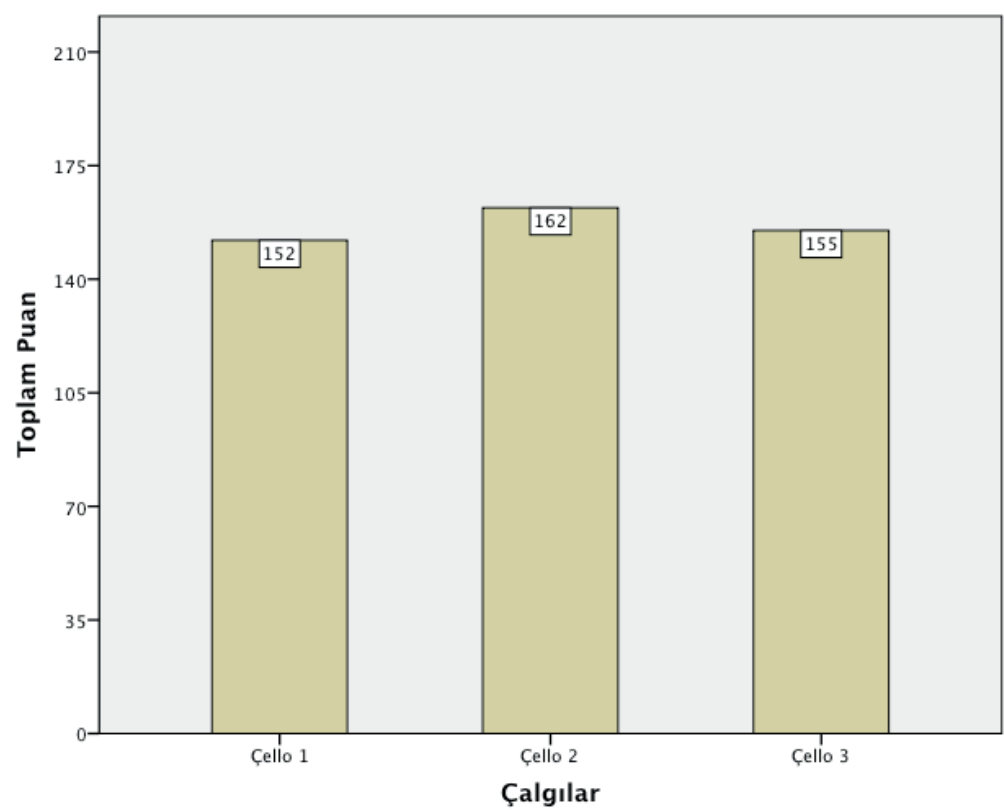

Grafik 2. Çalg1 Değerlendirme Ölçütlerine Göre Alınan Toplam Puan

Grafik 2'de, yedi değerlendirme kriteri üzerinden çalgıların aldıkları toplam puanlar görülebilmektedir. Uzman değerlendirmeleri sonucu, Çello 2 (162 puan) bu çalışmada en başarılı çalgı olmuştur. Onu birbirine yakın puanları ile sırasıyla Çello 3 (155 puan) ve Çello 1 (152 puan) takip etmektedir.

\section{Sonuç ve Öneriler}

Yaylı çalgılar şekilleri, yapı düzenleri ve cila tipleriyle diğer ağaç kasalı çalgılardan ayrılan pek çok detay ve incelik içeren çalgılardır. Bu karmaşık yapı, iyi entonasyonlu, ses ve tonal özellikleri üst düzey, rahat çalınabilir bir çalgıyı üretebilmek açısından çeșitli zorluklar teşkil etmektedir. Çalgı yapımcılarının daha iyi çalgılar ortaya koyabilmek adına icracılarla sürekli iletişim halinde kalarak, onlardan geri dönüşler almaları çok önemlidir. Bu dönüşleri sözlü almak sıklıkla karşılaşılan bir yol olsa da sözlünün yanında ya- 
zılı ve belki sayısal olarak da değerlendirilebilecek dönütler almanın değeri yadsınamaz. Dolayısı ile rubrik bu alanda etkili bir araç olacaktır.

Rubrik, yani dereceli puanlama anahtarı, ölçülebilir seviyede nesnelliğe izin veren bir değerlendirme metodu olarak bu çalışmada başarıyla uygulanmıştır. Değerlendirilen ölçütlerde başarıya göre puanlama cetveli sunmasıyla, hassas puanlamaya imkan sağlamıştır. Elde edilen verilere göre, çalışmada karşılaştırılan üç çellonun toplam puanları birbirine yakındır ve uzmanlarca benzer düzeyde başarılı bulunmuşlardır. Bununla birlikte YÇR'deki tüm ölçütler göz önünde bulundurulduğunda performansları ile birbirlerinden ayrılmışlardır. Bu farklılıklar YÇR'nin ayrıntılı puanlama sistemi sayesinde birbirinden net olarak ayrılabilmiştir. Rubrik, çalgıların güçlü yönlerini ayırabilmiş, benzer ses karakteristiğine sahip çalgıları ortaya çıarabilmiştir. Eski ve yeni çalgılar arasındaki ses karakteristiği farkını ve bu çalgıların birbirlerine göre üstün-zayıf noktaları ortaya çıkarmıştır. Çalışma ayrıca, çalgıların zayıf yönlerini ortaya çıkarıp özgün karakterlerini belirlemek ve ileride bunları geliştirmek adına rubriğin kullanışı bir metot olduğunu göstermiştir.

Sonuç olarak; rubrik, performansa dayalı önceden belirlenmiş dereceli puanlama sistemi sayesinde, öznel tercihleri ölçülebilir nesnel verilere dönüştürme anlamında başarılı bir araç olabildiğini göstermiştir. Araştırma sonucunda, çalgılar arası farkları ortaya çıkarmak için rubrik kullanımına ilişkin olarak aşağıdaki önerilere yer verilmiştir:

Akustik test olanağı olmayan durumlarda, çalgılar arası ses niteliklerini belirlemede rubrik, ölçülebilir düzeyde nesnel veriler sunabilir. Bunun için amaca uygun değerlendirme ölçütleri oluşturulmalıdır.

Rubrik, kurumsal satın almalarda, kalite kontrolü yapan komisyonca kullanılabilir.

Yeni ve eski çalgıların arasında tonal karakter farkı olacağı öngörülerek, rubriğin değerlendirme niteliklerinin her iki tip çalgının özelliklerini de kapsayacak ölçütlere göre oluşturulması gerekebilir.

Kullanılacak tüm ölçütler bizim çalışmamızda olduğu gibi alan uzmanlarının görüşleri doğrultusunda belirlenmelidir. Değerlendirme ölçütleri her alan için odaklı olmalı ve alanın ihtiyaçlarını karşılamalıdır. Ek olarak, puanlama skalası arttıılarak değerlendirme hassasiyeti/doğruluğu arttırılabilir. 
Çalg1 değerlendirmesinde daha kesin sonuçlar elde edebilmek için değerlendirici sayısı arttırılabilir, değerlendiren kişilere çalgı değerlendirme konusunda tecrübe kazandırılarak verim arttırılabilir.

Seri üretimde ya da satın alımlarda çok sayıda çalgıyı değerlendirmek gerekli olduğunda müzisyenler ve lütiyelerden oluşan komisyonlarca hazırlanacak rubriğe; çalgının yapısı, cilası, olası sağlık sorunları ile ilgili ek kriterlerin de eklenmesi uygun olabilir.

\section{Kaynakça}

Ang1, Ç., Birer, A. (2013). Keman öğretiminde karşılaşılan entonasyon problemleri ve çözüm önerileri. Sanat Eğitimi Dergisi, 1(2), 48-69.

Barutçugil, İ. (2002). Performans yönetimi. İstanbul: Kariyer Yayıncılık.

Duff, D. (1985). Sound quality in the cello. Canadian Acoustics, 13(4), 15-17.

Dünnwald, H. (1991). Deduction of objective quality parameters on old and new violins. Catgut Acoustical Society, $1(7), 1-5$.

Fritz, C., Curtin, J., Poitevineau, J., Borsarello, H., Wollman, I., Tao, F., Ghasarossian, T. (2014). Soloist evaluations of six Old Italian and six new violins. Proceedings of the National Academy of Sciences of the United States of America, 111(20), 7224-7229.

Fritz, C., Curtin, J., Poitevineau, J., Morrel-Samuels, P., Tao, F. (2012). Player preferences among new and old violins. Proceedings of the National Academy of Sciences of the United States of America, 109(3), 760-763.

İmik, Ü. ve Haşhaş, S. (2014). Çalgı kalitesinin performans ve başarıya etkilerine yönelik görüşler "bağlama örneği”. İnönü Üniversitesi Sanat ve Tasarım Dergisi, 4(9), 59-68.

Pagliaro, M. (2015). The string instrument owner's handbook. Maryland: Rowman \& Littlefield.

Parlak, B., Doğan, N. (2014). Dereceli puanlama anahtarı ve puanlama anahtarından elde edilen puanların uyum düzeyleri. Hacettepe Üniversitesi Eğitim Fakültesi Dergisi, 29(2), 189-197.

Popham, J. W. (1997). "What's wrong and what's right with rubrics”. Educational Leadership, 55(2), 72-75.

Şişman, Ç. (2010). Eğitim fakülteleri güzel sanatlar eğitimi müzik eğitimi bölümlerinde ve devlet konservatuarlarında lisans düzeyinde yaygın olarak kullanılan viyolonsel sol el ile ilgili metotların analizi. Yayımlanmamış Yüksek Lisans Tezi. İzmir: Dokuz Eylül Üniversitesi.

Yaygıngöl, H. S. (2006). Yaylı çalgı yapım teknolojisi-II. Eskişehir: Anadolu Üniversitesi. http://help.rcampus.com/index.php/Rubric (Erişim Tarihi: 01. 04. 2017) 